\title{
Analysis on the Man-Machine-Environment Collaborative Teaching Method for Mining Engineering Major
}

\author{
https://doi.org/10.3991/ijet.v11i10.6269 \\ Lang Liu ${ }^{1,2}$, Xuehua Sun ${ }^{1}$ and Ki-il Song ${ }^{3}$ \\ ${ }^{1} \mathrm{Xi}$ 'an University of Science and Technology, Xi'an, China; \\ ${ }^{2}$ Ministry of Education of China, Xi'an, China; \\ ${ }^{3}$ Inha University, Incheon, South Korea;
}

\begin{abstract}
Man, teaching equipment (machine), and teaching environment in the higher education system constitute the man-machine-environment system in the teaching system. In this study, modern higher pedagogy is combined with man-machine-environment system engineering. The teaching system is analyzed in the point of view of mining engineering profession and a new type of "man-machineenvironment collaborative teaching method" is proposed. Also, we conducted a comprehensive discussion about the academic problems in various aspects of composition, theoretical basis, and functional allocation by combining teaching reform features of the mining engineering profession. The practice of man-machine-environment collaborative teaching method strengthens students' learning of perceptual knowledge, alleviates difficulty of site visit and practice, and enables conducting an indoor interactive dynamic simulation experiment. Moreover, it cultivated the students' operational ability, spatial thinking, and global concept of industrial mining sites. Furthermore, it improved the autonomous learning ability of undergraduates, which was of great significance to cultivating innovative talents. Lastly, it transformed the teaching method from "teaching" to initiative "exploration" and "discovery" for students.
\end{abstract}

Index Terms-Man-machine-environment collaborative Teaching method, Mining engineering, Higher pedagogy, Man-machine-environment system engineering

\section{INTRODUCTION}

Since the term "teaching method" was introduced in the 1950 s, domestic and overseas higher education has been exploring effective teaching technology in engineering field. Differences in teaching thoughts or theories, teaching practice, learning contents, objectives, forms, and processes of teaching practice activities define various teaching methods[1-2].

In recent years, because multimedia and network technologies are rapidly developing toward digitalization, traditional higher teaching concept and teaching mode are facing numerous competitions and challenges, and correspondingly lots of reforms and innovations of teaching models were generated[3]. Some scholars have analyzed the effects of individual differences (i.e., gender, age, personality, motivation and learning strategies) to the teaching performance in the education system, and the research results were used to optimize the teaching process[4-5]. There were also some scholars, focusing on the study of teaching equipment and teaching tools such as multimedia technologies, networks and virtual reality (VR), etc., which were used to improve the teaching philosophies and teaching methods[6-7]. At the same time, some scholars have analyzed the influence of environment (i.e., school teaching environment, family environment and social environment) on the quality of teaching, and improved the teaching quality by optimizing the teaching environment[8-9]. However, considering the complexity of the college teaching system and the particularity of the mining engineering education, the existing research results have certain limitations, it is difficult to improve the whole education system by analyzing only one aspect, i.e., education receivers, teaching tools and education environment. Therefore, it is very necessary to establish a comprehensive consideration of the above three aspects, as well as putting forward a corresponding teaching model for the mining engineering education system.

From the point of system science, the teaching system of higher education is a complicated man-machineenvironment system engineering [10]. Based on the modern higher education theory and man-machineenvironment system theory, this study proposes a new type of "man-machine-environment collaborative teaching method" and conducts discussion and analysis on the suggested teaching method in various aspects such as theoretical basis and functional allocation, by combining teaching reform features of the mining engineering profession.

\section{Theoretical Basis Of The New Type OF TEACHING METHOD}

\section{A. Man-machine-environment system theory}

The man-machine-environment system is a compound system consisting of man, machine, and environment. Man-machine-environment system engineering is an optimal science that uses system science theory and system engineering method to correctly handle relationships among three elements - man, machine, and environment and conduct in-depth research of man-machineenvironment relations. The research object of this study is the man-machine-environment system and the research objectives are making an organic combination of man, machine, and environment; effectively giving significance to man's effect; providing people with safe, sanitary, and comfortable environment as much as possible which guarantees man's health, wellbeing, and joyous activities while maximizing man's working efficiency. Man in the man-machine-environment system refers to the operating subject of the activity. As the operating subject, man 
should be manipulating objects (machine and materials) and controlling the environment consciously and purposefully all the time while accepting the counteraction. Machine in this system is a generalized machine that refers to a generic name of all objects controlled by man. It includes instruments of labor, machines (equipment), means of labor, technological process, and other material elements related to man. Environment refers to the specific operating conditions in which man and machine coexist, including the natural environment, man-made environment, social environment, and others. The man-machineenvironment system regards "man," "machine," and "environment" as the three major elements of the system, and it establishes a complicated and large system through effects such as transferring, processing and controlling of information among the three elements.

\section{B. Information processing theory}

Gagnez was one of the most influential and famous educational psychologists in the 20th century. He believed that learning was a process with a beginning and an end. This process could be divided into several phases, and each phase must conduct different information processing. Incidents occurring in the information processing phases are called learning incidents. A learning incident is an internal processing undertaking of students, and it forms the basic structure of learning information processing theory. Correspondingly, the teaching process should not only be based on the internal processing undertaking of students but should also influence this process. Hence, the teaching phase completely corresponds to the learning phase. Incidents occurring in each teaching phase, namely, teaching incidents are external learning conditions. Teaching involves external conditions of teacher arrangement and control, and the art of teaching lies in complete consistency between the learning phase and the teaching phase. Information processing theory is not a name of a theory but a generic name of a kind of theory. Information theory regards man as an information processor, whereas man's consuming behavior is only an information processing process, namely, a process of information input, coding, processing, storing, extraction, and use.

\section{Directional Bias EFFECT On The AcCuracy OF MONITORING DATA}

Man (teacher, student, teaching administrator, etc.), machine (teaching equipment, i.e. multimedia, network, digital mines etc), and teaching environment (teaching environment, site environment of a mine, virtual teaching environment, social environment, etc.) found in the teaching of the mining engineering profession constitute the man-machine-environment system, which combines man-machine-environment system engineering and pedagogy [11-12]. Taking the teaching of the mining engineering as the starting point, this study analyzes the teaching system of the mining engineering from the perspective of man-machine-environment system engineering, constructs a teaching system coupling method of the mining engineering profession based on man-machine-environment system theory, and conducts a comprehensive discussion about academic problems in the aspects of composition, theoretical basis, and functional allocation by combining teaching reform features of the mining engineering profession.

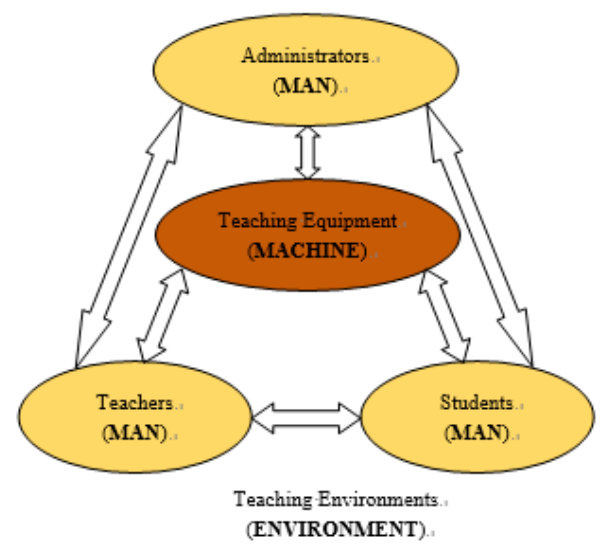

Figure 1. Combined model of man-machine-environment and higher education systems

In the coupling method between the higher educational teaching and the man-machine-environment systems, all people (including teachers, students, administrators, etc.) in the teaching environment of higher education have direct bi-directional relationships with teaching equipment. The teacher influences the cognition, emotion, and behaviors of students through equipment, and the students give a feedback of the teaching information through the teaching equipment. Moreover, the administrator coordinates the effective implementation of educational activities by managing teaching equipment, and he also adjusts management according to the teaching activities.

The new type of collaborative teaching method, which considers man-machine-environment system theory as guidance, takes full advantages of modern information technology and design strategies of teaching and learning; constructs a new type of teaching method led by teachers, which fully embodies the effect on students as cognitive subjects; and integrates "machine" and "environment" in the collaborative teaching system. This new type of teaching method emphasizes on students' participation in autonomous learning: stress on scenario creation, problem exploration, resource presentation, activity collaboration, language and words expression, and meaning construction.

\section{Functional Allocation Of The New Type OF TEACHING MODE}

Taking the mining engineering profession as an example, man, machine, and environment in the "manmachine-environment collaborative teaching method" exert their own functions together with the collaborative effects. The method also realizes an optimized allocation of resources in the education and teaching systems. Finally, it optimizes the learning efficiency of students.

\section{A. Composition and Functions of "Man"}

In the teaching system of the mining engineering profession, man factors mainly include students, teachers (full-time teachers and front-line mine workers), and teaching administrators. The specifically includes the following: (i) for the educated, as leading factors in the manmachine-environment system, their individual differences are the main factors of the learning effect of the mining profession. The educated find difficulty in applying influencing factors including uncontrollable factors such as 


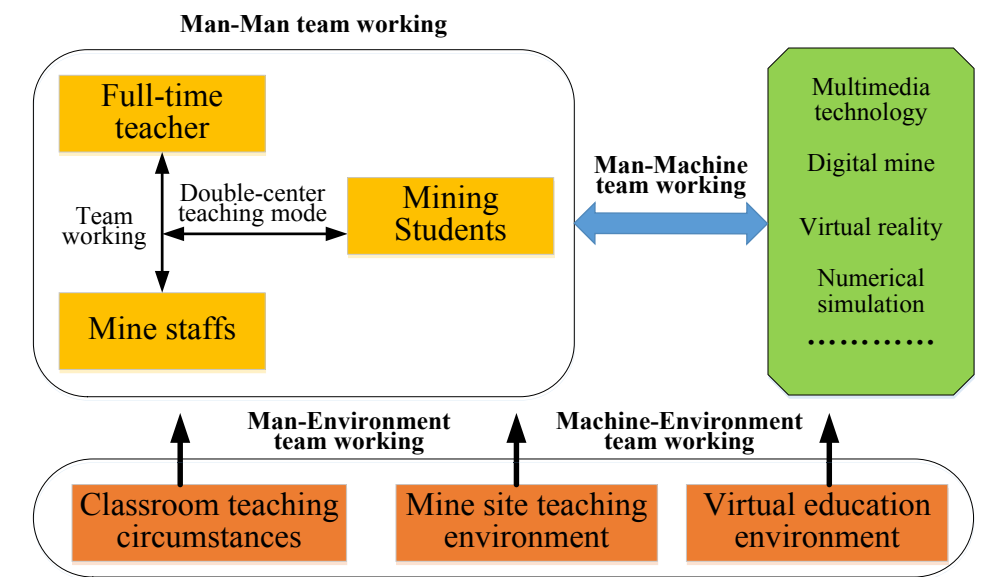

Figure 2. Man-machine-environment collaborative teaching mode for the mining engineering

gender, age, and character to themselves through their own efforts. Factors that can influence them are controllable factors, mainly including concept, motive, learning strategy, and others. (ii) Educators, "teachers are those who preach, tutor, and clear up confusions." They are the best annotation of the role of teachers and should have certain professional knowledge and skills and to students obtain knowledge and realize the inheritance of mining knowledge. (iii) Teaching administrators must make the teaching design, guarantee the orderly implementation of teaching, provide a good environment for teaching, enable the students to progressively master knowledge, and then comprehensively complete the teaching tasks.

The good qualities of educators are the keys to qualityoriented education and talent cultivation. High-quality education can be developed and the quality of education and teaching can be improved only by improving the basic quality of teachers. Management ability, management concept, and other aspects of education administrators influence teaching design, teaching environment, as well as hardware and software input in teaching in the whole teaching system of a college.

\section{B. Composition and Functions of "Machine"}

In this study, "machine" refers to a generalized machine relative to man, and its main effect is to transmit mining knowledge to students in the form of a medium. Since the 1990s, many researchers have extensively applied computer and new media technologies to teaching. Multimedia network teaching is the combination of computer multimedia technology, network communication technology, and modern educational theory, and it has incomparable collaboration, autonomy, opening, diversity, and creativity, which are not found in traditional teaching. Its features such as cognitive simulation, man-machine interface, and resource sharing not only greatly enrich teaching contents and expand communication channels, but also update educational concept and improve teaching efficiency.

In the new type of teaching method, "machine" is a generic name of all hardware and software for the implementation and guarantee of teaching activities. It is the material basis of school construction as well as the means of implementing teaching activities. In the information age, teaching equipment level has become an important symbol of school modernization, especially that modern teaching equipment such as computers and multimedia play significant roles in the teaching process of the mining profession and the learning process of mining knowledge.

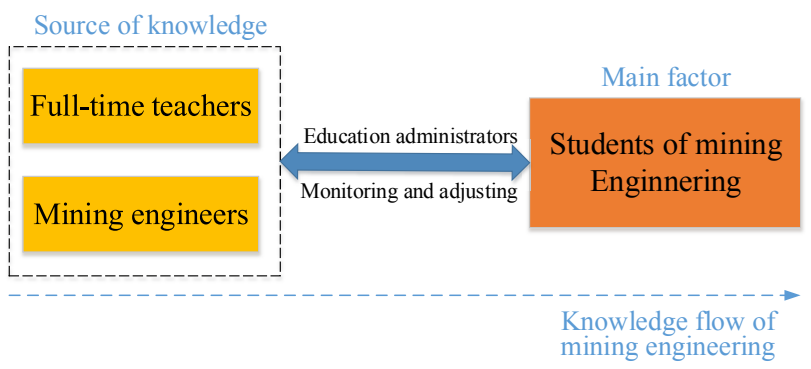

Figure 3. Composition and functions of "man" in the teaching system of the mining engineering

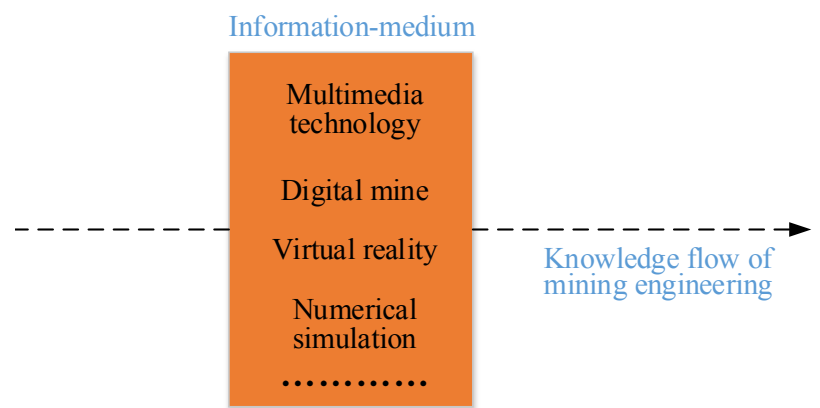

Figure 4. Composition and functions of "Machine" in the teaching system of the mining engineering profession

\section{Composition and Functions of "Environment"}

The definitions of education and teaching environment by domestic and overseas scholars commonly focus on the place and background of the teaching and learning environment. The former believes that the teaching and learning environment is a physical space or a place of learning. For example, Knirk F.G. from Technological Educational Institute, U.S. clearly defined learning environment as a learning place consisting of architecture, classroom, library, laboratory, playground, and learning area under a family environment. The latter defines teaching and learning environment from conditions that teaching and learning must meet and provide. For example, some scholars put forward that in school education, the teaching and learning environment mainly includes facilities and conditions such as school teachers, library, laboratory, and playground. The environment is an important factor for completing educational tasks, improving education quality, and realizing education and teaching objectives. It also includes learning conditions provided by the society and family in a broad sense. 
The positive and favorable teaching environment of the mining profession has five functions: guiding function, cohesive function, stimulating function, health function, and aesthetic education function. As subjects of the teaching environment, when accepting influence and restriction from the teaching environment, teachers and students continuously use their wisdom and hands to regulate, control, remold, and construct the teaching environment to suit their own physical and psychological development. Environment factors in the teaching system of the mining profession influence the exertion of functions of man and machine, and their effects run through the whole teaching process.

\section{Application Of The New Type Of Teaching METHOD}

To improve the learning efficiency of students majoring in mining engineering, a college established the manmachine interaction touch-screen teaching platform and used the man-machine-environment collaborative teaching mode to conduct teaching demonstration with obvious effects.

The system provided an autonomous learning platform for core courses - Coal Mining, Mine Ventilation and Sinking and Driving Engineering, and other courses in the mining engineering. In addition, it provided an autonomous learning platform for elective courses-Introduction to Mining and Introduction to Mine Dressing of relevant majors such as Geological Engineering, Engineering Mechanics, Mine Dressing Engineering, Safety Engineering, and Underground Engineering[13]. To establish this teaching method, supporting construction contents, which mainly include the following, is necessary: vertical type multimedia multi-point touch screen all-in-one machine display platform, mine and deposit 3D modeling animation display system, mining technology and animation display system, mining process animation display system, and others.

The establishment of the man-machine interactive touch-screen type teaching platform enhanced the students' learning of perceptive knowledge and relieved difficulty in on-site visit and practice. Moreover, an indoor interactive dynamic simulation experiment was conducted. It cultivated students' operating ability, spatial thinking ability, and overall concept of industrial mining sites. It also improved undergraduates' autonomous learning ability, which was greatly significant to cultivating innovative talents. In addition, it transformed the teaching mode from "teaching' to initiative "exploration" and "discovery" of students.

\section{CONCLUSION}

Man (e.g., teachers, students, teaching administrators, etc.), machine (e.g., multimedia, network, digital mine, etc.), and teaching environment (e.g., teaching environment, site environment of mine, virtual teaching environment, social environment, etc.) found in the teaching of the mining engineering field constitute the man-machine-environment system in the teaching of the mining engineering profession. Through the new type of "man-machine-environment collaborative teaching mode" in the teaching process of the mining engineering profession and with a comprehensive consideration of the features of the mining engineering profession, this study analyzed functional allocation from perspectives of man,

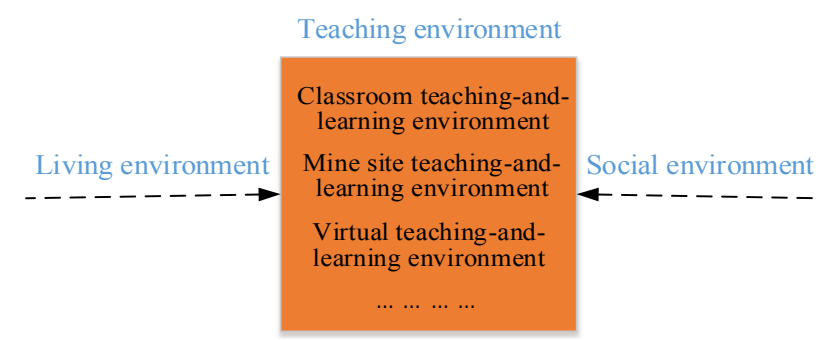

Figure 5. Composition and functions of "Environment" in the teaching system of the mining engineering

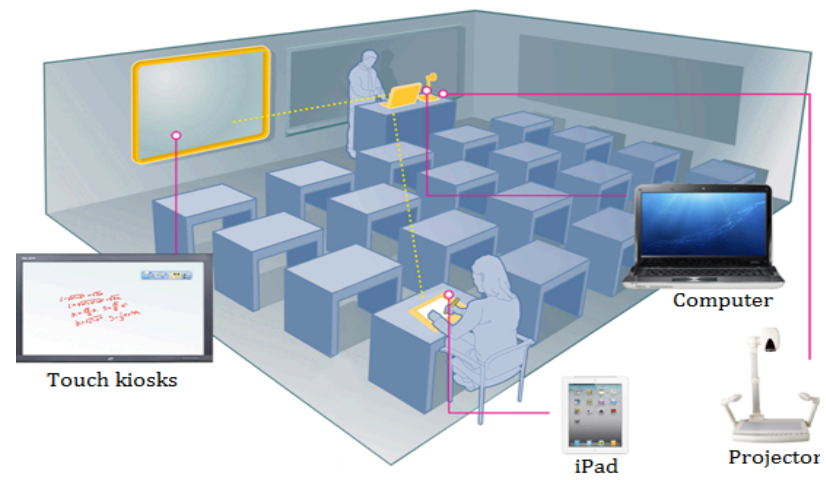

Figure 6. Teaching system diagram based on man-machineenvironment collaborative teaching mode

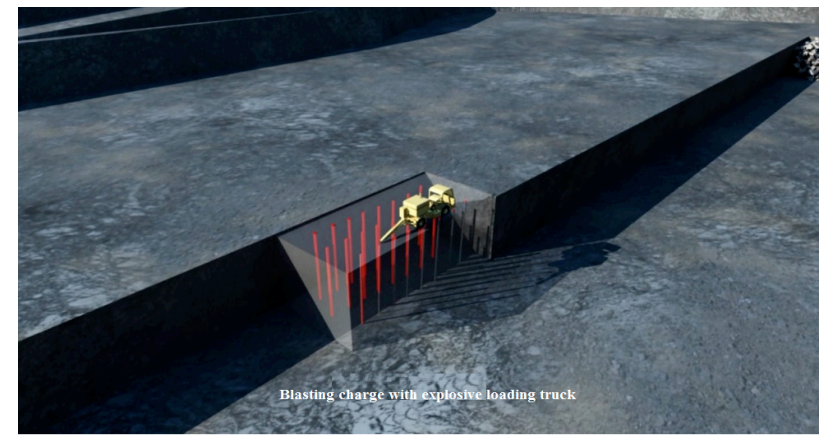

(a)

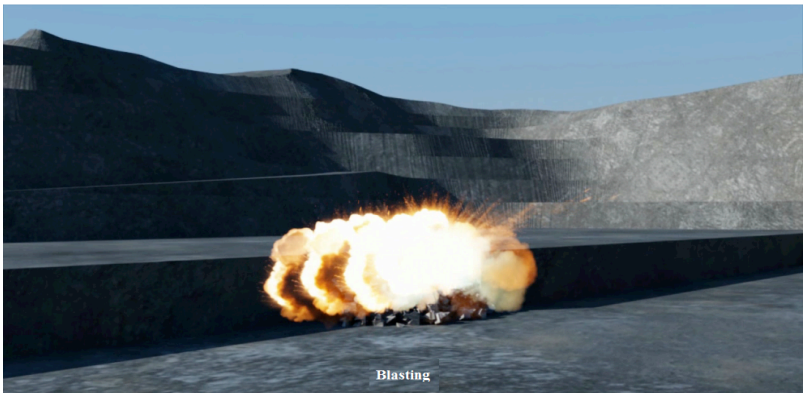

(b)

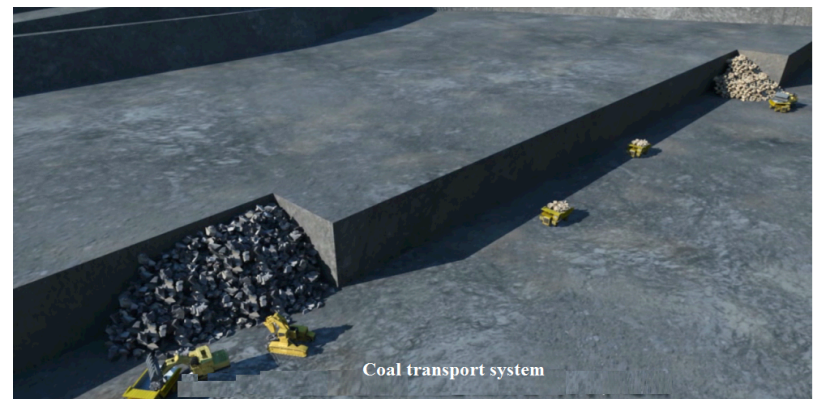

(c)

Figure 7. Mining teaching platform of man-machine-environment interactive touch screen (taking blast of open-pit mining for example) 
machine, and environment under this teaching system as well as the interactions among these elements. System engineering optimized the mining teaching system structure, optimizing the acceptance of the professional education of students majoring in mining engineering. This study aims to provide a new research method for higher education and teaching reform to stimulate domestic and overseas scholars in order to propose practical and effective reform schemes for higher education and teaching.

\section{REFERENCES}

[1] Yuan Z G, "New conception of education", Science and Education Press, December 2002.

[2] Liu Y C, "Building the new teaching pattern under the information era", Journal of Yunnan University of Finance and Economics, vol. 21, no. supplement, pp. 274-275, June 2005.

[3] Ding Y L, "Ergonomics (revised edition)", Beijing Institute of Technology Press, July 2000.

[4] Muelas A, Navarro E, "Learning strategies and academic achievement", Procedia - Social and Behavioral Sciences, vol. 165, no. 1, pp. 217-221, January 2015. http://dx.doi.org/10.1016/ j.sbspro.2014.12.625

[5] Ganzach Y, Gotlibovski C, "Individual differences and the effect of education on religiosity", Learning and Individual Differences, vol. 36, no. 12, pp. 213-217, December 2014. http://dx.doi.org/10.1016/j.lindif.2014.10.007

[6] Chen S Y, Xia Y J, "Research on Application of Multimedia Technology in College Physical Education", Procedia Engineering, vol. 29, no. 1, pp. 4213-4217, January 2012. http://dx.doi.org/10.1016/j.proeng.2012.01.645

[7] Sampaio A Z, Ferreira M M, Rosário D P, Martins O P, "3D and VR models in Civil Engineering education: Construction, rehabilitation and maintenance", Automation in Construction, vol. 19, no. 7, pp. 819-828, November 2010. http://dx.doi.org/10.1016/ j.autcon.2010.05.006

[8] Chanut P, Thanita L, "Relationship between motivational goal orientations, perceptions of general education classroom learning environment, and deep approaches to learning", Kasetsart Journal of
Social Sciences, vol. 37, no. 2, pp. 100-103, May-August 2016. http://dx.doi.org/10.1016/j.kjss.2015.01.001

[9] Fraser B J, "Environments for Education (Second Edition)", International Encyclopedia of the Social \& Behavioral Sciences, July 2015.

[10] Gong X P, Muhetaer Z, Huang G, Dai X G, Shi Z M, "On the reform and problems of mining engineering specialty in China", High Education of Science, no. 3, pp. 58-63, March 2010.

[11] Wang B W, "Discussion on teaching method of geotechnical engineering course in mining major", Education for Chinese Afterschool, no. 4, pp. 61-62, April 2011.

[12] Wang C, Chen S J, Zhao Z H, "Application of mine solid model in mining Teaching", China Education Innovation Herald, no. 1, pp. 127, January 2011.

[13] Li J Z, Chen H Z, Sui G, "Study on simulation system of fully mechanized mining face", Journal of System Simulation, vol. 19, no. 18, pp. 4164-4167, September 2007.

\section{AUTHORS}

Lang Liu (corresponding author) is an associate professor in Energy School, Xi'an University of Science and Technology, Xi'an, 710054 China and is with the Key Laboratory of Western Mines and Hazards Prevention, Ministry of Education of China, Xi'an, 710054 China. (e-mail: csuliulang@163.com).

Xuehua Sun is with the College of Science and Technology, Xi'an University of Science and Technology, Xi'an, 710054 China. (spring_xue@163.com).

Ki-il Song is an associate professor in Dept. of Civil Engineering, Inha University, Incheon, 402-751 South Korea. (E-mail: ksong@inha.ac.kr)

The authors are grateful for the support provided by the National Natural Science Foundation of China (No. 51674188, 51504182), the Natural Science Basic Research Plan of Shaanxi Province of China (No.2015JQ5187), the Scientific Research Program funded by the Shaanxi Provincial Education Department (No.15JK1466), the Project funded by China Postdoctoral Science Foundation (No.2015M582685), and the Xi'an University of Science and Technology Research Fund Program for Young Scholars (No.2014-NY-018). Submitted 23 Septembr 2016. Published as resubmitted by the authors 24 October 2016. 